Pacific Journal of Mathematics

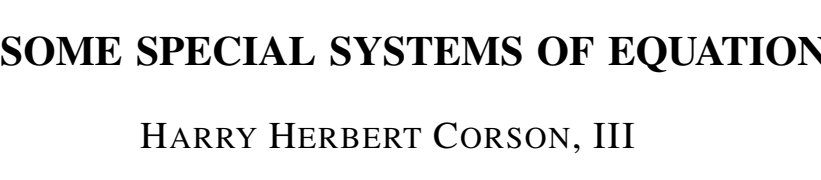




\title{
ON SOME SPECIAL SYSTEMS OF EQUATIONS
}

\author{
H. H. CoRson
}

1. Let $\mathbf{F}$ be an arbitrary field. Let $S$ be a system of equations which, when solved for two of its variables, takes the following form:

$$
\begin{aligned}
& x_{1}^{k_{1}}=f\left(x_{3}, \cdots, x_{n}\right), \\
& x_{2}^{k_{2}}=g\left(x_{3}, \cdots, x_{n}\right),
\end{aligned}
$$

where $f$ and $g$ are arbitrary functions of the indicated variables. Consider also the equation

$$
y^{k_{1} k_{2}}=f^{s k_{2}}\left(y_{3}, \cdots, y_{n}\right) g^{r k_{1}}\left(y_{3}, \cdots, y_{n}\right) \text {. }
$$

THEOREM 1. If $\left(k_{1}, k_{2}\right)=1$ and $r k_{1}+s k_{2}=1$, then the distinct solutions of (1) in $F$ with $x_{1} x_{2} \neq 0$ may be put in one-to-one correspondence with the distinct solutions of (2) in $F$ with $y \neq 0$. Moreover, these solutions of (1), $x_{1} x_{2} \neq 0$, may be determined from the solutions of (2), $y \neq 0$, and conversely, by means of transformations (3) and (4) below.

Proof. Assuming for the rest of this section that $x_{1} x_{2} \neq 0, y \neq 0$, we put

$$
\begin{aligned}
& x_{1}=y^{k_{2}}\left\{\frac{f\left(y_{3}, \cdots, y_{n}\right)}{g\left(y_{3}, \cdots, y_{n}\right)}\right\}^{r}, \\
& x_{2}=y^{k_{1}}\left\{\frac{g\left(y_{3}, \cdots, y_{n}\right)}{f\left(y_{3}, \cdots, y_{n}\right)}\right\}^{s}, \\
& x_{i}=y_{i}
\end{aligned}
$$$$
(i=3, \cdots, n)
$$

and notice that if $\left(y, y_{3}, \cdots, y_{n}\right)$ is a solution of (2) then (3) determines a solution of (1). Now let

$$
\begin{aligned}
& y=x_{1}^{s} x_{2}^{r}, \\
& y_{i}=x_{i} \quad(i=3, \cdots, n) .
\end{aligned}
$$

It may be verified directly that if $\left(x_{1}, x_{2}, \cdots, x_{n}\right)$ is a solution of (1) then (4) determines a solution of (2). Further, given a solution $\left(x_{1}, x_{2}\right.$, $\left.\cdots, x_{n}\right)$ of (1) and a solution $\left(y, y_{3}, \cdots, y_{n}\right)$ of (2) with $x_{i}=y_{i}(i=3, \cdots$, $n)$, then (3) implies (4) and conversely-which may be verified with the use of the relation $r k_{1}+s k_{2}=1$. 
We note that Theorem 1 may be extended by induction to apply to a system like (1) with an arbitrary number of equations, with $z_{1}^{k_{1}}$, $z_{2}^{k_{2}}, \cdots, z_{m}^{k m}$ as left members, and with arbitrary functions of $z_{m+1}, \cdots$, $z_{n}$ as right members if $\left(k_{i}, k_{j}\right)=1, i \neq j$. The argument is the same in going from $n$ to $n+1$ equations, and transformations corresponding to (3) and (4) may be constructed.

Use will also be made of the fact that Theorem 1 is still valid if $x_{3}, \cdots, x_{n}$ are restricted to values in $A$, a subset of $F$, as long as $y_{3}$, $\cdots, y_{n}$ are similarly restricted.

2. Let $\mathbf{F}$ now be a finite field $G F(q), q=p^{t}$. Assume $f$ and $g$ to be homogeneous polynomials of degrees $m_{1}$ and $m_{2}$ respectively, where $\left(m_{1}, k_{1}\right)=1$ and $\left(m_{2}, k_{2}\right)=1$. The solutions of (2) can be determined by the following method used by Hua and Vandiver [1] and Morgan Ward [2].

As $\left(k_{1} k_{2}, s k_{2} m_{1}+r k_{1} m_{2}\right)=1$, there are integers $a, b$, and $c$ such that $a k_{1} k_{2}+b\left(s k_{2} m_{1}+r k_{1} m_{2}\right)+c(q-1)=1$ with $(a, q-1)=1$. First assuming that $y \neq 0$, set

$$
y=\lambda^{a}
$$

$$
y_{i}=\lambda^{-b} z_{i} \quad(i=3, \cdots, n) .
$$

Equation (2) then assumes the following form:

$$
\lambda=f^{s k_{2}}\left(z_{3}, \cdots, z_{n}\right) g^{r k_{1}}\left(z_{3}, \cdots, z_{n}\right) .
$$

Thus every choice of $z_{3}, \cdots, z_{n}$ such that $f \neq 0, g \neq 0$ determines a solution of (2).

Now consider the system (1). Determine as above integers $u, v$, and $w$ such that $u k_{2}+v m_{2}+w(q-1)=1,(u, q-1)=1$. Assuming $x_{2} \neq 0$, set

$$
\begin{aligned}
& x_{2}=\gamma^{u} \\
& x_{i}=\gamma^{-v} t_{i} \quad(i=3, \cdots, n) .
\end{aligned}
$$

It is readily seen that all values of $t_{3}, \cdots, t_{n}$ such that $f\left(t_{3}, \cdots, t_{n}\right)=0$ determine solutions of the system (1) whether $g\left(t_{3}, \cdots, t_{n}\right)=0$ or not.

The same argument is valid if $g$ is assumed zero, which proves the following.

THEOREM 2. If $f$ and $g$ are homogeneous polynomials of degrees $m_{1}$ and $m_{2}$ respectively, $\left(m_{1}, k_{1}\right)=1$ and $\left(m_{2}, k_{2}\right)=1$, then the total number of solutions of the system (1) in $G F(q)$ is $q^{n-2}$

A similar application of Theorem 1 is the following. First let $S$ be 


$$
\begin{aligned}
& x_{1}^{k_{1}}=a_{3} x_{3}^{e m}+a_{4} x_{4}^{e m m_{4}}+\cdots+a_{n} x^{e m_{n}} \\
& x_{2}^{k_{2}}=b_{3} x_{3}^{d m_{3}}+b_{4} x_{4}^{d m_{4}}+\cdots+b_{n} x_{n}^{d m_{n}}
\end{aligned}
$$

where $\left(k_{1}, k_{2}\right)=1$. Also if $M$ is the least common multiple of $m_{3}, \cdots$, $m_{n}$, assume $\left(e M, k_{1}\right)=1$ and $\left(d M, k_{2}\right)=1$. In place of (5) we employ the following transformation in (2), following Carlitz [3]:

$$
\begin{aligned}
y & =\lambda^{a} \\
y_{i} & =\lambda^{-b M / m_{i}} z_{i} \quad(i=3, \cdots, n),
\end{aligned}
$$

where $a k_{1} k_{2}+b M\left(s k_{2} e+r k_{1} d\right)+c(q-1)=1,(a, q-1)=1$. Exactly as above follows the next theorem.

THEOREM 3. The total number of solutions of (8) subject to the conditions stated above is $q^{n-2}$.

Also [3] suggests the following generalization of Theorem 2. Let $f_{3}\left(x_{3}\right), f_{4}\left(x_{4}\right), \cdots, f_{n}\left(x_{n}\right)$ and $g_{3}\left(x_{3}\right), g_{4}\left(x_{4}\right), \cdots, g_{n}\left(x_{n}\right)$ be homogeneous polynomials of degrees $e m_{3}, e m_{4}, \cdots, e m_{n}$ and $d m_{3}, d m_{4}, \cdots, d m_{n}$ respectively, where now $\left(x_{i}\right)=\left(x_{i 1}, x_{i 2}, \cdots, x_{i s_{1}}\right)(i=3, \cdots, n)$. Thus by the same argument follows the next theorem.

TheOREM 4. Replacing in (8) $x_{i}^{e m_{i}}$ by $f_{i}\left(x_{i}\right)$ and $x_{i}^{a m_{i}}$ by $g_{i}\left(x_{i}\right),(i=3$, $\cdots, n)$, then the total number of solutions of the resulting system is $q^{s_{3}+\cdots+s_{n}}$.

3. Now let $\mathbf{F}$ be the rational field and let $f$ and $g$ in (1) be polynominals with integral coefficients. If $x_{3}, \cdots, x_{n}$ are restricted to be integers, then $x_{1}$ and $x_{2}$ in any solution must be integers.

In the equation $r k_{1}+s k_{2}=1$ we may assume that $r>0, s<0$. In place of system (1) write

$$
\begin{aligned}
& x_{1}^{\prime k_{1}}=\frac{1}{x_{1}^{k_{1}}}=\frac{1}{f\left(x_{3}, \cdots, x_{n}\right)}=f^{\prime}\left(x_{3}, \cdots, x_{n}\right) \\
& x_{2}^{k_{2}}=g\left(x_{3}, \cdots, x_{n}\right) .
\end{aligned}
$$

we assume as in Theorem 2 that $f$ and $g$ are homogeneous of degrees $m_{1}$ and $m_{2}$ respectively, $\left(m_{1}, k_{1}\right)=1$ and $\left(m_{2}, k_{2}\right)=1$. Let $a, b$ and $c$ satisfy $a k_{1} k_{2}+b\left(r k_{1} m_{2}-s k_{2} m_{1}\right)+c(q-1)=1,(a, q-1)=1$; then (5) determines a family of solutions in integers of

$$
y^{k_{1} k_{2}}=f^{\prime s k_{2}}\left(y_{3}, \cdots, y_{n}\right) g^{r k_{1}}\left(y_{3}, \cdots, y_{n}\right),
$$

$y \neq 0$. By Theorem 1, (3) determines a family of solutions of (10) with 
$x_{3}, \cdots, x_{n}$ integers, and by the remark at the first of this section, a family of solutions of equations (1) with $x_{1}, x_{2}, \cdots, x_{n}$ integers, $x_{1} x_{2} \neq 0$. The cases where $f$ or $g$ is zero may be treated as in $\S 2$, which proves the following.

THEOREM 5. If $f$ and $g$ are homogeneous polynomials with integral coefficients of degrees $m_{1}$ and $m_{2}$ respectively, $\left(m_{1}, k_{1}\right)=1$ and $\left(m_{2}, k_{2}\right)=1$ then a family of solutions in integers may be found for equations (1) by the method above.

See [2] for remarks on the solution of equation (11) under the above hypotheses. Note especially the above method does not in general give all solutions.

I should like to thank Professor L. Carlitz for his very helpful interest in this material.

\section{REFERENCES}

1. L. Carlitz, The number of solutions of certain types of equations in a finite fleld. Pacific J. Math. 5 (1955), 177-181.

2. L. K. Hua and H. S. Vandiver, On the nature of the solutions of certain equations in a finite field, Proc. Nat. Acad. Sci. U.S.A. 35 (1949), 481-487.

3. Morgan Ward, A class of soluble diophantine equations, Proc. Nat. Acad. Sci. U.S.A. 37 (1951), 113-114.

DUKE UNIVERSITY 


\section{PACIFIC JOURNAL OF MATHEMATICS}

\section{EDITORS}

\author{
H. L. Royden \\ Stanford University \\ Stanford, California \\ E. Hewitt \\ University of Washington \\ Seattle 5 , Washington
}

R. P. Dilworth

California Institute of Technology

Pasadena 4, California

\author{
A. HorN* \\ University of California \\ Los Angeles 24, California
}

\section{ASSOCIATE EDITORS}

\author{
E. F. BECKENBACH \\ C. E. BURGESS \\ H. BUSEMANN \\ H. FEDERER
}

\author{
M. HALL \\ P. R. HALMOS \\ V. GANAPATHY IYER \\ R. D. JAMES
}

\author{
M. S. KNEBELMAN \\ I. NIVEN \\ T. G. OSTROM \\ M. M. SCHIFFER
}

J. J. STOKER

G. SZEKERES

F. WOLF

K. YOSIDA

\section{SPONSORS}

\author{
UNIVERSITY OF BRITISH COLUMBIA \\ CALIFORNIA INSTITUTE OF TECHNOLOGY \\ UNIVERSITY OF CALIFORNIA, BERKELEY \\ UNIVERSITY OF CALIFORNIA, DAVIS \\ UNIVERSITY OF CALIFORNIA, LOS ANGELES \\ UNIVERSITY OF CALIFORNIA, SANTA BARBARA \\ MONTANA STATE UNIVERSITY \\ UNIVERSITY OF NEVADA \\ OREGON STATE COLLEGE \\ UNIVERSITY OF OREGON \\ UNIVERSITY OF SOUTHERN CALIFORNIA
}

STANFORD RESEARCH INSTITUTE

STANFORD UNIVERSITY

UNIVERSITY OF UTAH

WASHINGTON STATE COLLEGE

UNIVERSITY OF WASHINGTON

AMERICAN MATHEMATICAL SOCIETY HUGHES AIRCRAFT COMPANY SHELL DEVELOPMENT COMPANY

Mathematical papers intended for publication in the Pacific Journal of Mathematics should be typewritten (double spaced), and the author should keep a complete copy. Manuscripts may be sent to any of the editors. Manuscripts intended for the outgoing editors should be sent to their successors. All other communications to the editors should be addressed to the managing editor, Alfred Horn at the University of California, Los Angeles 24, California.

50 reprints of each article are furnished free of charge; additional copies may be obtained at cost in multiples of 50 .

The Pacific Journal of Mathematics is published quarterly, in March, June, September, and December. The price per volume (4 numbers) is $\$ 12.00$; single issues, $\$ 3.50$. Back numbers are available. Special price to individual faculty members of supporting institutions and to individual members of the American Mathematical Society: $\$ 4.00$ per volume; single issues, $\$ 1.25$.

Subscriptions, orders for back numbers, and changes of address should be sent to Pacific Journal of Mathematics, c/o University of California Press, Berkeley 4, California.

Printed at Kokusai Bunken Insatsusha (International Academic Printing Co., Ltd.), No. 10, 1-chome, Fujimi-cho, Chiyoda-ku, Tokyo, Japan.

* During the absence of E. G. Straus.

PUBLISHED BY PACIFIC JOURNAL OF MATHEMATICS, A NON-PROFIT CORPORATION COPYRIGHT 1956 BY PACIFIC JOURNAL OF MATHEMATICS 


\section{Pacific Journal of Mathematics}

\section{Vol. 6, No. $3 \quad$ BadMonth, 1956}

Richard Arens and James Eells, Jr., On embedding uniform and topological spaces ............................................ 397

N. Aronszajn and Prom Panitchpakdi, Extension of uniformly continuous transformations and hyperconvex metric spaces .............. 405

Kai Lai Chung and Cyrus Derman, Non-recurrent random walks ........ 441

Harry Herbert Corson, III, On some special systems of equations . . . . . . . . . 449

Charles W. Curtis, On Lie algebras of algebraic linear transformations . . . 453

Isidore Heller, Neighbor relations on the convex of cyclic permutations . . . . 467

Solomon Leader, Convergence topologies for measures and the existence of transition probabilities..................................... 479

D. H. Lehmer, On certain character matrices ...................... 491

Michael Bahir Maschler, Minimal domains and their Bergman kernel function ........................................... 501

Wm. M. Myers, Functionals associated with a continuous transformation ................................... 517

Irving Reiner and Jonathan Dean Swift, Congruence subgroups of matrix groups ....................................... 529

Andrew Sobczyk, Simple families of lines ................... 541

Charles Standish, A class of measure preserving transformations ........ 553 Jeremiah Milton Stark, On distortion in pseudo-conformal mapping ..... 565 